\title{
Experience with direct molecular diagnosis of fragile $\mathrm{X}$
}

\author{
J C Mulley, S Yu, A K Gedeon, A Donnelly, G Turner, D Loesch, C J Chapman, \\ R J M Gardner, R I Richards, G R Sutherland
}

Department of Cytogenetics and Molecular Genetics, Adelaide Children's Hospital, North Adelaide, South Australia 5006, Australia.

J C Mulley

$S$ Yu

A K Gedeon

A Donnelly

R I Richards

G R Sutherland

Tumbatin

Developmental Clinic, Prince of Wales Children's Hospital, High Street,

Randwick, NSW 2031 ,

Australia.

G Turner

Department of

Psychology, La Trobe

University, Bundoora,

Victoria 3083

Australia.

D Loesch

Department of

Paediatrics, School of

Medicine, University

of Auckland,

Auckland, New

Zealand.

C J Chapman

Medical Genetics,

Department of

Paediatrics, Dunedin

Hospital, Dunedin,

New Zealand.

R J M Gardner

Correspondence to

Dr Mulley.

Received 22 October 1991

Revised version accepted

21 January 1992 .

\section{Abstract}

The utility of the pfxa3 probe for direct molecular diagnosis of the fragile $X$ (FRAXA) has been established. This probe detects amplification of an unstable DNA element consisting of variable length CCG repeats. The size of the amplified fragment is correlated with phenotype and was determined using Pst digested DNA in family members. In 35 families with the fragile $X$, there was correspondence in 183 cases between the presence of an amplified unstable element and the presence of the fragile $X$ chromosome independently determined by cytogenetics, position in the pedigree, or linked DNA markers flanking the fragile $X$. There was also correspondence in 124 cases between the presence of the normal 1.0 kb Pst fragment and absence of the fragile $X$ chromosome independently determined by linked flanking markers. Six additional families considered to be isolated cases of 'fragile $X$ ' had been diagnosed before recognition of FRAXD. The pfxa3 probe confirmed the cytogenetic diagnosis in three families, the other three being rediagnosed as non-fragile $X$. A further two families had consistent expression of a different folate sensitive fragile site, FRAXE, close to $F R A X A$ but not associated with fragile $X$ syndrome and not detectable with the pfxa3 probe. Subsequent referrals were received from additional family members or from members of new families for whom carrier status had not been predetermined by linked markers. Direct pfxa3 diagnosis for the 135 females within these 222 additional cases was confirmed by dosage analysis with the control probe pS8. Independent confirmation of the primary pfax3 diagnosis was helpful for correct diagnosis of females because of a small proportion who had an unstable element expressed as a faint smear of bands and because of the occasional presence of high molecular weight bands from incomplete Pst digestion. Diagnosis was definitive for all males using pfxa3 alone in the presence of only one $X$ chromosome.
Fragile $\mathrm{X}$ syndrome is the most common familial type of mental retardation in humans. The syndrome is associated with the folate sensitive fragile site at $\mathrm{Xq} 27.3$ ( FRAXA). Families with fragile $\mathrm{X}$ syndrome had been previously ascertained on the basis of cytogenetic demonstration of the fragile site in a mentally impaired family member.

Genetic counselling for family members has been complicated by three factors. These are incomplete penetrance of cytogenetic expression of the fragile site in a proportion of female carriers, the occurrence of transmitting males who have the fragile $\mathrm{X}$ genotype but do not show mental impairment, and the presence of a common fragile site, $F R A X D$, ar $\mathrm{Xq} 27.2^{1}$ which can be expressed at low frequency under the same conditions used to detect the fragile $\mathrm{X}$. Transmitting males (defined as unaffected carrier males who have reproduced or have the potential to reproduce) have been detected either by risk analysis using closely linked polymorphic markers flanking the fragile $\mathrm{X}^{2}$ or by their position in the pedigree. The occurrence of these asymptomatic male carriers is a unique phenomenon among $\mathrm{X}$ linked genetic disorders. However, the most puzzling phenomenon associated with fragile $\mathrm{X}$ has been the Sherman paradox, ${ }^{34}$ suggesting a progressive increase in severity from generation to generation.

Molecular characterisation of the fragile X in three laboratories ${ }^{5-7}$ has made possible a direct test for the fragile $\mathrm{X}$ genotype in affected families. The existence of transmitting males, and the Sherman paradox, are now explicable in terms of the increase in size from generation to generation of the heritable unstable DNA element which is the molecular basis for this disorder. ${ }^{5689}$ This unstable element consists of variable lengths of a repeating CCG trinucleotide sequence. ${ }^{810}$ The size of the Pst I fragment containing this repeat is $1.0 \mathrm{~kb}$ in normal X chromosomes. ${ }^{8-10}$ What initiates amplification of the $1.0 \mathrm{~kb}$ fragment transforming it into a fragile $X$ is not known; however, once the process has begun there is a direct correlation between the intellectual component of the fragile $\mathrm{X}$ phenotype, cytogenetic expression of the fragile site, and length of the unstable element which characterises the fragile $\mathrm{X}$ genotype. ${ }^{9}$ Whether the correlations between phenotype and length of the unstable element, and between cytogenetic 
expression and length of the unstable element, represent continuous relationships, or stepwise relationships with discontinuity at a PstI fragment size of approximately $1.6 \mathrm{~kb}$, cannot be resolved without additional data. ${ }^{9}$ Females with larger amplifications (greater than $1.6 \mathrm{~kb}$ ) were either normal or mentally affected, implying that additional factors such as non-random $\mathrm{X}$ inactivation may contribute to intellectual phenotype in females. The unstable element usually increases in size from one generation to the next when transmitted by females, but when transmitted by males remains the same size or decreases. The larger sized elements are somatically unstable and can present as multiple bands on Southern blots. ${ }^{5689}$

\section{Materials and methods PROBES}

The pfxa3 probe is a 536 bp DNA fragment excised from pUC18 using the restriction endonuclease Pst I. The pfxa3 target sequence is located immediately distal to the unstable element which comprises the fragile $X .{ }^{5}$ The pfxa3 probe detects a $1.0 \mathrm{~kb}$ fragment on Southern blots of PstI digested DNA from non-fragile $\mathrm{X}$ chromosomes, while the unstable fragile $\mathrm{X}$ element appears as a fragment of higher molecular weight. The pS8 probe is an 800 bp fragment excised from pUC19 using Pst I. This sequence was derived from a YAC containing the VK21 sequence and is used as an internal positive control probe in double hybridisation with the pfxa 3 probe on Pst I

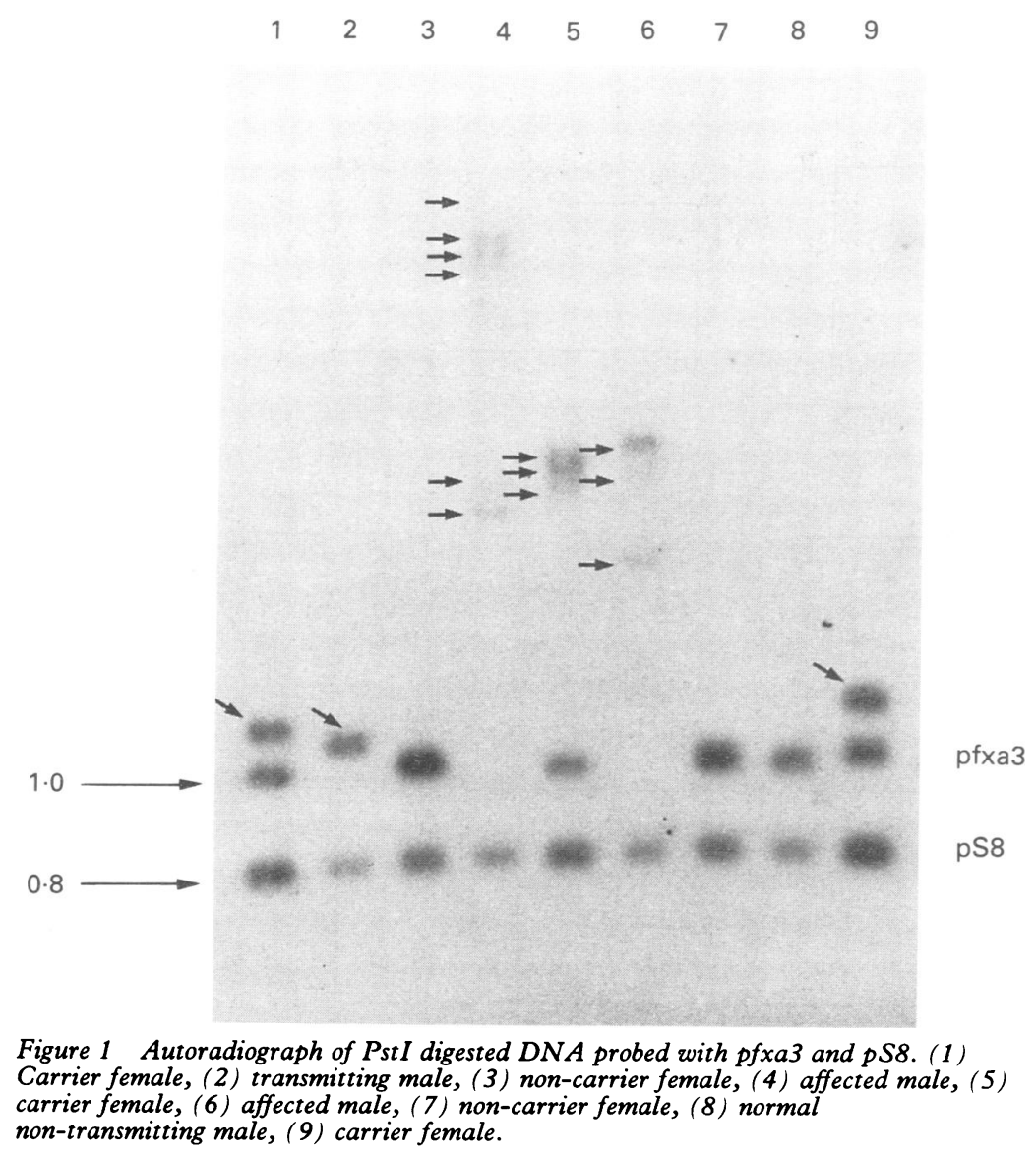

filters. It detects an $800 \mathrm{bp}$ fragment on Southern blots. An autoradiograph showing the pfxa 3 and pS8 fragments is shown in fig 1 . The pfxa3 probe is available from Oncor, Inc, Box 870, Gaithersburg, MD 20884, USA.

\section{HYBRIDISATION CONDITIONS}

Hybridisation was carried out at $42^{\circ} \mathrm{C}$ in $5 \times$ SSPE (pH 7.4), $1 \%$ SDS, $50 \%$ formamide, $10 \%$ dextran sulphate, and $100 \mu \mathrm{g} / \mathrm{ml}$ salmon sperm DNA. Filters were washed in $0.1 \%$ SDS and $0.1 \times \operatorname{SSC}(0.015 \mathrm{~mol} / 1$ sodium chloride and $0.0015 \mathrm{~mol} / 1$ sodium citrate) at $70^{\circ} \mathrm{C}$ for at least 30 minutes. The high stringency wash at $70^{\circ} \mathrm{C}$ is crucial for removal of lane background, presumably related to the high GC content of the probe, in order to visualise clearly the unstable element band or bands.

\section{AC REPEAT MARKERS AT THE FRAGILE $X$}

Two AC repeat markers detectable by the polymerase chain reaction (PCR) have been described: FRAXAC1 and FRAXAC2 within $10 \mathrm{~kb}$ of the fragile $\mathrm{X}^{11}$ and $D X S 548150 \mathrm{~kb}$ from the fragile $\mathrm{X} .{ }^{7}$ Of the two within $10 \mathrm{~kb}$ of the fragile $\mathrm{X}, F R A X A C 2$ is the more informative (heterozygosity $71 \%$ ). FRAXAC1 is in strong linkage disequilibrium with $F R A X A C 2$ and is therefore redundant for diagnosis. Primer sequences and reaction conditions were given by Richards et al. ${ }^{11}$

\section{RISK ANALYSIS}

Carrier risks were computed for unaffected subjects in 35 fragile $\mathrm{X}$ families using linked DNA markers as previously described ${ }^{12}$ but with closer markers. ${ }^{213}$ Risk analysis was applied to families where more than one subject had been clearly diagnosed by cytogenetic expression of the fragile $\mathrm{X}$ and this provided confirmation of pfxa3 diagnosis for unaffected subjects. Cytogenetic diagnosis had previously been carried out and thus provided confirmation of pfxa3 diagnosis for affected subjects. The map of linked markers used in the risk analysis was based on that previously established. ${ }^{213}$ This differs only very slightly from the map subsequently determined from the CEPH (Centre d'Etude du Polymorphisme Humain) families ${ }^{14}$ using the microsatellite markers FRAXAC1 and FRAXAC2 to represent the fragile site locus. ${ }^{11}$

BASIS FOR DIAGNOSIS USING THE pfXa3 PROBE Pst I digests are the most instructive since they give the necessary resolution on Southern analysis to distinguish male transmitters from normal males, to separate male transmitters from affected males, and to differentiate normal females from carrier females ${ }^{9}$ (fig 1). Diagnosis is unambiguous in males. Hybridisation with Pst I digested chromosomal DNA gives a $1.0 \mathrm{~kb}$ band in normal non-transmitting males, a band of up to $1.6 \mathrm{~kb}$ in male transmitters of the fragile $\mathrm{X}$, and one or more bands of greater than $1.6 \mathrm{~kb}$ in males with fragile $\mathrm{X}$ syndrome. 
Where there is a smear of bands there may be bands within the 1.0 to $1.6 \mathrm{~kb}$ range in addition to bands in excess of $1.6 \mathrm{~kb}$. Male transmitters and affected males do not have a band of normal intensity in the $1.0 \mathrm{~kb}$ position and usually have no band in the $1.0 \mathrm{~kb}$ position when the CCG repeat has been amplified.

Pst I digested DNA usually gives only a $1.0 \mathrm{~kb}$ band in the normal non-carrier females. Occasionally a doublet at $1.0 \mathrm{~kb}$ is detectable in non-carrier females who have two alleles at the extremes of the normal range of allele sizes for the CCG polymorphism. In all affected carrier females and some of the unaffected carrier females the pfxa 3 probe hybridises to a $1.0 \mathrm{~kb}$ fragment from the normal chromosome plus a fragment or fragments of greater than $1.6 \mathrm{~kb}$ from the fragile $\mathrm{X}$ chromosome. A faint smear of fragments greater than $1.6 \mathrm{~kb}$ in size may be difficult to detect. Unaffected carrier females all have either a $1.0 \mathrm{~kb}$ band and a band of up to $1.6 \mathrm{~kb}$ or the same pattern as the affected females; thus, the pfxa3 probe cannot predict the intellectual phenotype of females when the PstI fragment exceeds $1.6 \mathrm{~kb}$. Carrier females with fragment size or sizes exceeding $1.6 \mathrm{~kb}$ usually express the fragile site cytogenetically, whereas females with a fragment size of $1.6 \mathrm{~kb}$ or less usually have only a single abnormal fragment which is clearly visible and they do not express the fragile site cytogenetically. ${ }^{9}$ Unlike males with a CCG amplification, females always have a clearly visible $1.0 \mathrm{~kb}$ fragment from the normal $\mathrm{X}$ chromosome.

\section{Results and discussion}

DETECTION OF FEMALE CARRIERS AND MALE TRANSMITTERS

An example of diagnosis using the pfxa 3 probe for one of the 35 families examined (which contained more than one carrier on the basis of cytogenetic analysis) is shown in fig 2 . This pedigree shows those features routinely encountered in direct fragile $\mathrm{X}$ diagnosis using the pfxa3 probe. The unstable element can be seen to increase in size from generation II $(1.2 \mathrm{~kb})$ to generation $\mathrm{V}(3.2 \mathrm{~kb})$ with development of multiple bands (in IV.1, IV.19, and V.2) associated with the increase in size. The fragile $\mathrm{X}$ was detected using pfxa3 for all affected boys for whom DNA was available (IV.1, IV.10, V.1). The obligate male transmitter (II.4) had a $1.2 \mathrm{~kb}$ fragment and the probable male transmitter $(99.8 \%$ risk) (III.6) had a $1.3 \mathrm{~kb}$ fragment. The women shown to have the fragile $\mathrm{X}$ by cytogenetics were confirmed as carriers using the pfxa3 probe (IV.2, IV.8, IV.19, V.2). The obligate female carriers for whom DNA was available, who did not express the fragile $\mathrm{X}$ (II.2, III.3, III.8, III.9, III.13, IV.5), were all shown to have abnormal pfxa3 fragments. Two women (IV.17 and IV.18) ascertained as probable carriers (99\%) using linked markers were shown as definite carriers using pfxa3. The remaining family members at low risk using linked markers (III.1, III.5, IV.3, IV.6, IV.9, IV.11, IV.13, IV.14, IV.15, IV.16, IV.20, IV.21) were confirmed as non-carriers using the pfxa3 probe.

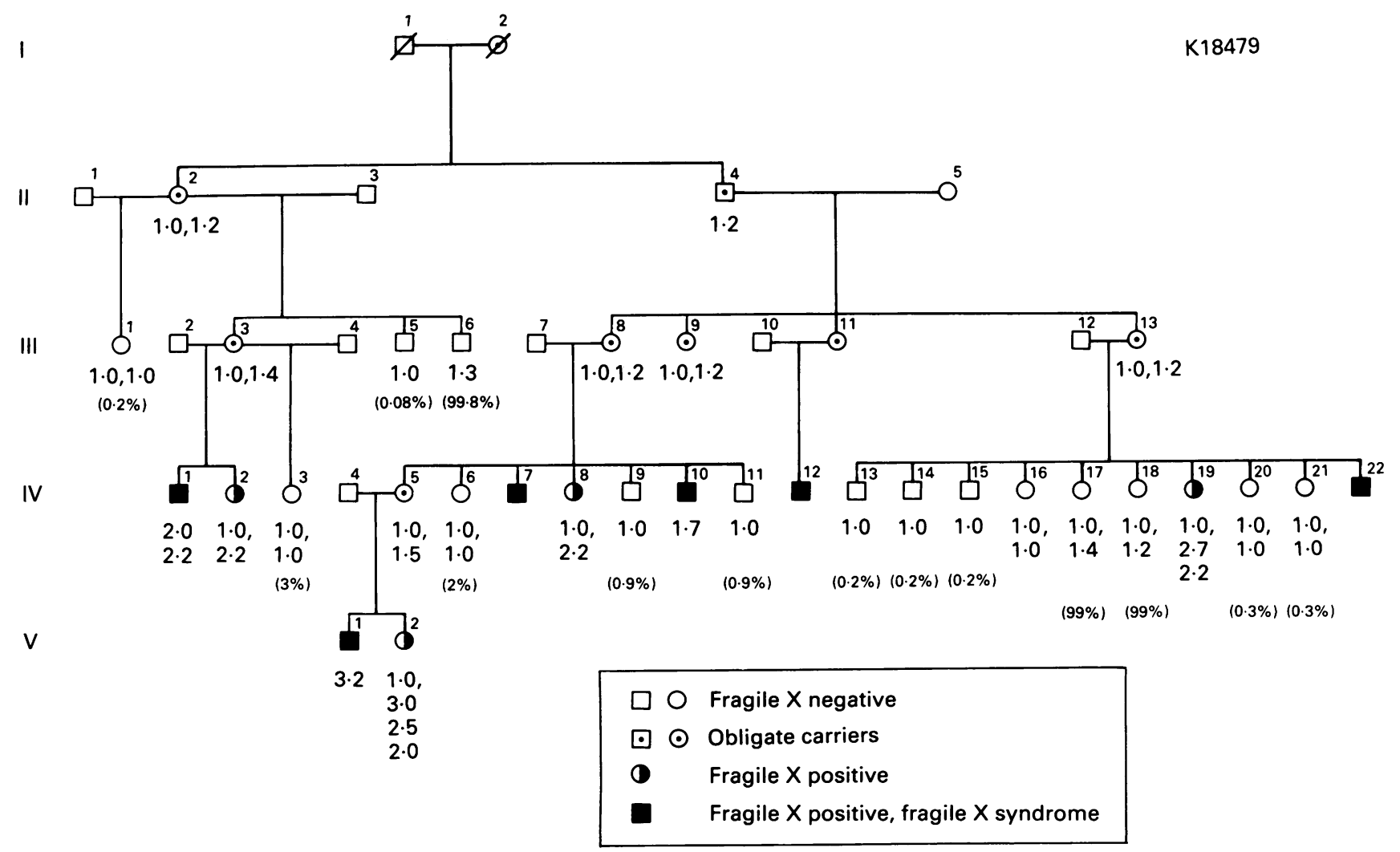

Figure 2 Fragile $X$ pedigree showing typical behaviour of the unstable element detectable with pfxa3. The pfxa3 genotype is shown for subjects from whom DNA was collected and consists of the normal $1.0 \mathrm{~kb}$ allele and the alleles of variable and abnormal size associated with the unstable element. Corresponding risks determined by linkage analysis are shown in parentheses and were based on pairwise flanking markers from within the set DXS292, DXS297, DXS304, and DXS52. (Marker genotypes are not shown.) 
Fragile $X$ diagnoses carried out using the pfxa3 probe.

\begin{tabular}{|c|c|c|c|c|c|}
\hline \multicolumn{3}{|c|}{ Males } & \multicolumn{3}{|c|}{ Females } \\
\hline \multirow[t]{2}{*}{ Normal } & \multirow[t]{2}{*}{ Transmitters } & \multirow[t]{2}{*}{ Affecteds } & \multirow[t]{2}{*}{ Non-carriers } & \multicolumn{2}{|c|}{ Carriers } \\
\hline & & & & $\begin{array}{c}\text { Cytogenetically } \\
\text {-ve }\end{array}$ & $\begin{array}{c}\text { Cytogenetically } \\
+ \text { ve }\end{array}$ \\
\hline $\begin{array}{ll}\text { (A) } & P r \\
53 & \end{array}$ & by linked DNA & $\begin{array}{c}s(n=307) \\
60\end{array}$ & 71 & 64 & 46 \\
\hline $\begin{array}{l}\text { (B) } \mathrm{N} \\
47\end{array}$ & sed by linked I & $\begin{array}{c}\underset{33}{\operatorname{arkers}(n}=2 \\
33\end{array}$ & 61 & 47 & 27 \\
\hline
\end{tabular}

Results for the remaining 34 families where diagnosis had been predetermined by linked markers were of the same pattern (data not shown). Diagnosis was carried out for a total of 307 family members (table A). Detection by pfxa3 of a $1.0 \mathrm{~kb}$ Pst I fragment from the $195 \mathrm{X}$ chromosomes of all non-carrier females and normal males (independently assessed by linked markers) in these 35 families excluded the possibility of polymorphism at the PstI sites. Non-cleavage at either PstI site could have generated fragments of higher molecular weight indistinguishable from fragments containing CCG amplifications. In general, the unstable element responsible for fragile $\mathrm{X}$ genotype increased in size from generation to generation when transmitted by females, but not when transmitted by males (fig 2). Occasionally there was a small decrease in the size of the unstable fragments when transmitted from one generation to the next. In fig 1 , for example, the carrier mother in lane 1 has a $1.3 \mathrm{~kb}$ fragment which reduces to $1.2 \mathrm{~kb}$ in her male transmitter son, shown in lane 2 . In one unresolved case a normal pfxa 3 fragment in double dose was detected from a female with no abnormal fragment, who had a carrier haplotype determined by the AC repeat markers $D X S 297, D X S 548(150 \mathrm{~kb}$ proximal to $F R A X A$ ), and $F R A X A C 2$ (within $10 \mathrm{~kb}$ and distal to $F R A X A$ ). This apparent contradiction might arise from a sample error causing misinterpretation of linkage data or from contraction of an amplified fragment during transmission from mother to daughter.

All subsequent referrals (222 cases from confirmed fragile $\mathrm{X}$ families), in which carrier status had not been predetermined by linked markers, were assessed using the pfxa 3 and pS8 probes hybridised to PstI digested DNA (table B). Frequently, subjects from fragile $\mathrm{X}$ families had heard of recent progress in the diagnosis of the fragile $\mathrm{X}$ and requested testing when their pregnancy had been confirmed (in the case of females) and when pregnancy for their daughters had been confirmed (in the case of potential male transmitters). The 135 female genotype results determined by direct diagnosis alone agreed with dosage analysis. In one case of male transmission a significant decrease in the size of the unstable element was observed. A mildly affected male with a smear of Pst I bands ( $1.8 \mathrm{~kb}$ to $2.1 \mathrm{~kb})$ had reproduced and passed on a fragment of $1.3 \mathrm{~kb}$ to one daughter and $1.2 \mathrm{~kb}$ to his other daughter.

\section{DOSAGE ANALYSIS}

Results of pfxa3 hybridisation may be uncertain in females if the Pst I digest gives a 'smear' of weakly hybridising bands. This may be resolved using $E c o$ RI digests (where the normal band is $5 \mathrm{~kb}$ ). Using EcoRI, the differences in the lengths of the multiple bands are not so great and the 'cluster' of amplified bands (not shown) is easier to detect.

However, homozygosity or heterozygosity for the normal $1.0 \mathrm{~kb}$ fragment assessed by the absence or presence of an abnormal fragment associated with fragile $X$ genotype can be easily confirmed by dosage analysis on the Pst I digests. This involves comparison of signal intensity of pfxa3 compared with pS8 using the same PstI blot used to make the primary pfxa3 diagnosis. Such a comparison is advisable for females in the absence of confirmatory linkage studies, since abnormal bands in the higher molecular weight range often occur as weakly hybridising multiple bands and can be easily obscured by small amounts of background hybridisation. For example, in fig 1 the intensity of the $1.0 \mathrm{~kb}$ fragment of pfxa 3 is less than that of pS8 in the carrier females in tracks 1,5 , and 9 owing to the presence of only a single dose of DNA from only one $\mathrm{X}$ chromosome. In the normal females in tracks 3 and 7 the intensity of the $1.0 \mathrm{~kb}$ fragment of pfxa 3 is clearly greater than that of pS8 owing to the presence of two doses of DNA from two normal X chromosomes.

While relative intensity of the pfxa3 fragment compared with the pS8 fragment may vary from one hybridisation to the next, depending on variations in concentration and labelling efficiency of each of the probes, the ratio of the $1.0 \mathrm{~kb}$ pfxa3 fragment to the $0.8 \mathrm{~kb}$ pS8 fragment within lanes for any one hybridisation remains constant such that it is possible to verify the primary diagnosis of carrier status. This dosage analysis is independent of the amount of DNA in different lanes, the relationship between the 1.0 pfxa3 fragment and pS8 is constant for comparison between normal males and normal females (fig 1, tracks 3, 7, and 8), and the procedure was found to be reliable if the intensity of the $1.0 \mathrm{~kb}$ pfxa 3 and $0.8 \mathrm{~kb} \mathrm{pS} 8$ hybridising fragments were approximately equivalent. Assessment of dosage agreed with observed presence or absence of the pfxa3 fragment for the 135 females tested (table B). Dosage analysis cannot be applied to the amplified pfxa 3 fragment because of the propen- 
A

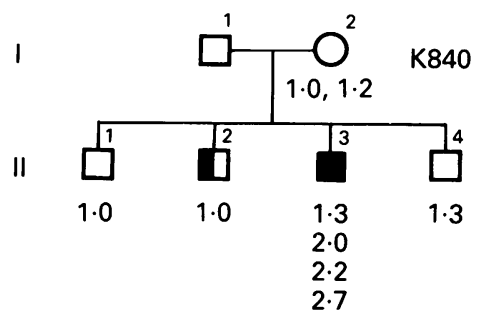

Figure 3 (A) Family with an isolated male with fragile $X$ syndrome. (B) Family with an isolated affected female. Genotypes for pfxa3 from PstI digested $D N A$ are shown on the pedigrees.

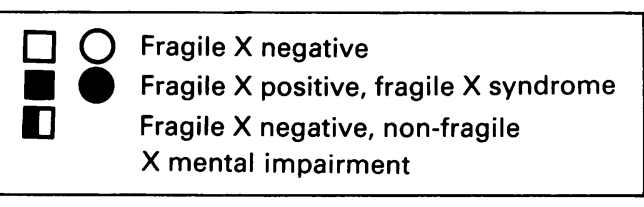

sity to form multiple bands arising from somatic instability.

\section{FAMILIES WITH ISOLATED CASES OF FRAGILE $X$} SYNDROME

In addition to the familial cases described above, there were families with isolated cases which were confirmed as fragile $\mathrm{X}$ by detection of the unstable amplified fragment using pfxa3. Two of these families are shown in fig 3. Fig 3A shows a family with an isolated male (II.3) affected with fragile $\mathrm{X}$ syndrome. A smear of bands confirms the diagnosis for II.3. Observation of a $1.3 \mathrm{~kb}$ band for one of his brothers (II.4) was the only means of showing that this brother was a male transmitter. The observation of a $1.2 \mathrm{~kb}$ band for their mother (I.2) was also the only means of showing that she was a carrier and that II.3 was not a new mutation. A normal $1.0 \mathrm{~kb}$ band for II. 2 confirms that his mental impairment is unrelated to the fragile $\mathrm{X}$, in agreement with existing cytogenetic analysis which did not detect the fragile $X$, and the clinical observation of a nonfragile X phenotype. Neither II.1 nor II.2 carries the fragile $\mathrm{X}$ mutation.

An isolated female with fragile $\mathrm{X}$ syndrome is shown in fig 3B. Diagnosis of IV.6 as a definite carrier could not be made before analysis by pfxa3. Even with highly polymorphic AC repeat markers at the fragile $X$, such a diagnosis is unlikely to be made by linkage unless genotypes for I.1, I.2, II.1, II.2, II.4, and II. 5 could all be inferred.

The possibility of new mutation as a cause for isolated cases of fragile $\mathrm{X}$ syndrome has been excluded for all cases examined so far. ${ }^{9}$ Recognition that 'isolated' cases of fragile $\mathrm{X}$ are all familial has had considerable impact on genetic counselling given to their relatives. Clarification of carrier status for relatives of such isolated cases has only been possible since the availability of direct molecular diagnosis.

EXCLUSION OF FRAGILE X SYNDROME

At the time when analysis of the initial 35 familial cases had been completed, six isolated cases had at least $2 \%$ of cells positive by cytogenetics and had been diagnosed as fragile $\mathrm{X}$ syndrome. Three of these six cases were
B

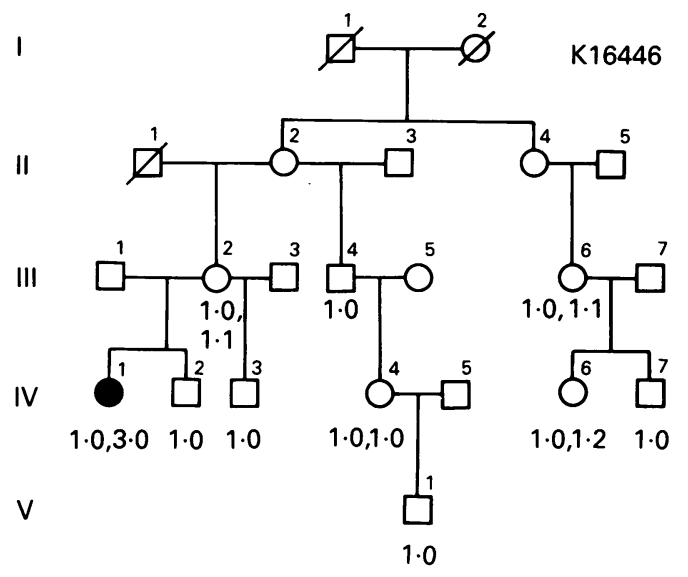

reclassified as non-fragile $\mathrm{X}$ syndrome on the basis of normal pfxa3 fragments from Pst I digested DNA. During the search for new mutations, ${ }^{9}$ further isolated cases which had been 'prediagnosed' by cytogenetics were selectively sought from collaborators in order to expand the number available for study. Of these, five isolated cases from a total of 11 were reclassified as non-fragile $X$ syndrome on the basis of normal pfxa3 fragments from PstI digested DNA. The proportion of such cases within collections from various laboratories will vary depending upon the quality of the cytogenetic analysis and on how recently this analysis was carried out. The existence of a common fragile site, $F R A X D$, at $\mathrm{Xq} 27.2$ is now well established ${ }^{1}$ and is one explanation for misdiagnosis in cases completed before recognition of $F R A X D$. Isolated cases of fragile $\mathrm{X}$ should be retested using a probe which detects the unstable element. Thus, the pfxa3 probe can be used to establish or exclude the diagnosis of fragile $\mathrm{X}$ syndrome for isolated cases in addition to determination of carrier status of males and females in families where the primary diagnosis has been established by unequivocal cytogenetics and confirmed by molecular analysis.

The problem of false positive cytogenetic diagnosis based on low rates of 'expression' is not restricted to isolated cases. They have been made within fragile $\mathrm{X}$ families and identified by linked flanking markers. ${ }^{15}$ Where false positive cytogenetic diagnoses could only be detected within families in the past by using linked markers, they are now easily ascertained using molecular diagnosis.

\section{A NEW RARE FOLATE SENSITIVE FRAGILE SITE,} FRAXE

At the time when analysis of the first 35 familial cases had established the reliability of the pfxa 3 probe for diagnosis, the pfxa 3 probe failed to detect an unstable element in the 'fragile X' family reported by Romain and Chapman. ${ }^{16}$ This family was unusual in that the 'fragile $\mathrm{X}$ ' carriers did not have fragile $\mathrm{X}$ syndrome despite consistent expression of a folate sensitive fragile site at Xq27.3. The likely explanation is the presence in this family of a distinct fragile site, $F R A X E$, which has no 


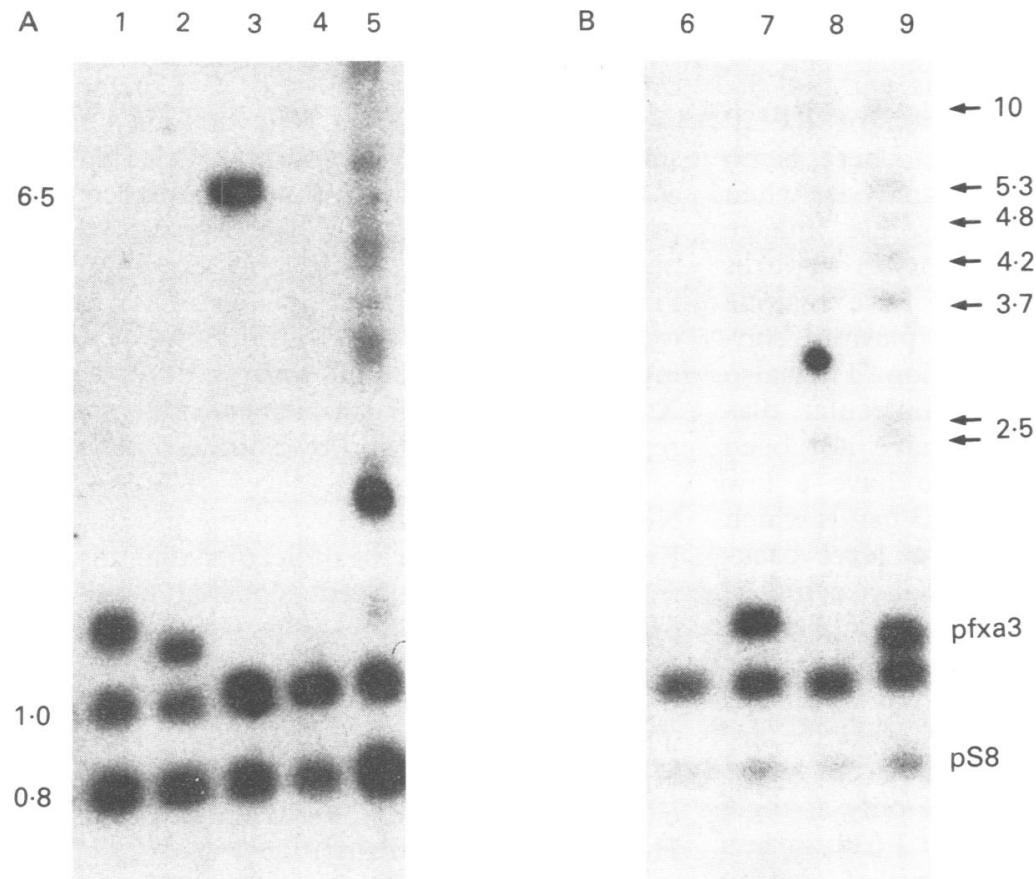

Figure 4 ( $A$ ) A contaminating plasmid band of $6.5 \mathrm{~kb}$ is shown for a male in track 3. Track 5 shows incomplete digestion of DNA from a carrier female. (B) Tracks 8 and 9 show the pattern of incomplete digestion observed where digestion has proceeded almost to completion. (1) Carrier female, (2) carrier female, (3) normal male, (4) normal male, (5) carrier female, (6) normal male, (7) carrier female, (8) normal male, (9) carrier female. In $(A)$ relative intensity of pfxa 3 and $p S 8$ bands is approximately equivalent and can be used for dosage analysis to confirm carrier status of females. In $(B)$ the $p S 8$ hybridisation is inadequate for reliable dosage analysis.

phenotypic effect but which maps in close proximity to $F R A X A$. The family of Romain and Chapman ${ }^{16}$ was described before the availability of pfxa 3 analysis and has features similar to two other families that have been reported which have high fragile $\mathrm{X}$ expression without mental retardation. ${ }^{617}$ The families tested so far $^{616}$ did not show the amplified pfxa3 fragment. In another recent ascertainment, FRAXE was shown to map distal to $F R A X A$ by in situ hybridisation using probes near $F R A X A{ }^{18}$ This confirms the existence of at least one other rare folate sensitive fragile site locus, $F R A X E$, located very close to $F R A X A$. The FRAXE site is not related to fragile $\mathrm{X}$ syndrome (associated with $F R A X A$ ) and is not the common fragile site $(F R A X D)$ which is proximal to $F R A X A$.

\section{ARTEFACTS}

One pedigree showed a $6.5 \mathrm{~kb}$ fragment in three generations which mimicked mendelian inheritance. This fragment was unrelated to the pfxa3 detectable fragment, as indicated by dosage of the $1.0 \mathrm{~kb}$ pfxa 3 allele, stability in 'transmission' from generation to generation, and presence of the $1.0 \mathrm{~kb}$ fragment in one man who also had the $6.5 \mathrm{~kb}$ fragment. It was confirmed as plasmid contamination by checking earlier autoradiographs used to analyse linked markers from the same DNA source and by reprobing the pfxa3 filter with plasmid sequence. Fig 4A shows the contaminating plasmid band and the pattern arising from what we interpret as incomplete digestion in a carrier female. Fig 4B shows clearer patterns of incomplete digestion. These artefacts need to be distinguished from abnormal pfxa3 fragments in order to avoid false positive molecular diagnosis.

\section{PRENATAL DIAGNOSIS}

The first prenatal diagnosis using the pfxa3 probe has been described fully elsewhere. ${ }^{19}$ Fragile $\mathrm{X}$ genotype was detected in a male fetus and confirmed by cytogenetics and the informative flanking markers DXS296 and $D X S 297$. No evidence for somatic variation was found in fetal tissues suggesting that the size of the unstable element should be useful for predicting the phenotype prenatally as well as postnatally. Prediction of phenotype at prenatal diagnosis should be made with extreme caution when fragment sizes are close to $1.6 \mathrm{~kb}$ since this basis for separation of male transmitters from affected males has as yet been determined from only crude measurement of Pst I fragment size on Southern blots. ${ }^{9}$ Prenatal diagnosis has also been reported using the probe $\mathrm{Ox} 1.9 .^{20}$

If prenatal diagnosis is to be carried out more rapidly than is possible by Southern analysis, it needs to be based on PCR technology using highly polymorphic markers at or very close to the fragile $\mathrm{X}$. When by Southern analysis the signal associated with abnormal pfxa3 fragments in some carrier females is weak (fig 1), extended exposure may be necessary to exclude the possibility of a false negative result. This is not a problem if the fetus is male where diagnosis can be carried out just as readily by observed absence of a normal $1.0 \mathrm{~kb}$ PstI fragment as by observation of abnormal size of the pfxa3 fragment, when the pS8 band is clearly present as a positive control (fig 1). PCR based diagnosis by linked AC repeat markers would provide rapid exclusion; however, a positive PCR diagnosis by linkage would need the additional pfxa3 result. Carrier males would be predicted to be mentally unaffected transmitters if the PstI fragment size was $1.6 \mathrm{~kb}$ or less and mentally affected if it exceeded $1.6 \mathrm{~kb}$. Carrier females would be predicted to be mentally unaffected if the PstI fragment size was $1.6 \mathrm{~kb}$ or less. However, unlike males, there are at present insufficient data to enable phenotypic prediction for a female fetus who has a specific Pst I fragment size which is greater than $1.6 \mathrm{~kb}$. Having eliminated the possibility of mental impairment for carrier females with Pst I fragment sizes of $1.6 \mathrm{~kb}$ or less, the remaining carrier females with Pst I fragment sizes exceeding $1.6 \mathrm{~kb}$ must as a group be at greater risk of mental impairment than the risks given for the unsubdivided group. ${ }^{4}$ These risks were $32 \%$ when the fragile $\mathrm{X}$ was passed through an unimpaired mother and $55 \%$ when passed through an impaired mother.

\section{Conclusions}

The pfxa3 probe is a reliable diagnostic tool for detecting fragile $\mathrm{X}$ genotype and predicting fragile $\mathrm{X}$ phenotype when applied to Pst $\mathrm{I}$ digested DNA. Used in conjunction with the pS8 probe, results may be checked for consistency by dosage analysis. Alternatively, used in 
conjunction with closely linked and highly polymorphic AC repeat markers, results may be confirmed by family analysis without the need for laborious determination of RFLP markers by Southern analysis. There is no need for computerised risk analysis when using markers virtually in absolute linkage with FRAXA. These confirmatory procedures guard against the possibility of false positive molecular diagnosis caused by plasmid contamination or incomplete digestion. They also guard against false negative molecular diagnosis in those females who have not been cytogenetically tested and who have a low intensity smear of abnormal pfxa 3 bands which could be easily masked by low level background. Such females are usually cytogenetically positive and therefore are unlikely to be misdiagnosed when parallel cytogenetic examination has been carried out. Carrier females who are cytogenetically negative are detectable without difficulty using the pfxa3 probe because they usually have only a single strongly hybridising fragment of $1.6 \mathrm{~kb}$ or less apart from the normal $1.0 \mathrm{~kb}$ fragment. Confirmatory family studies involving the $\mathrm{AC}$ repeat markers FRAXAC2 or DXS548 could be considered for inclusion in routine diagnostic protocols, not only to confirm the pfxa3 diagnosis and to carry out rapid PCR based prenatal diagnosis of genotype, but also to check for sample misidentification which can cause both false positive and false negative results.

The advent of molecular diagnosis raises the question of the role of cytogenetic analysis. Cytogenetic and molecular procedures will continue to be carried out in parallel until laboratories gain experience in molecular diagnosis. The initial ascertainment of fragile $\mathrm{X}$ families with amplification of the CCG repeat is likely to continue to be made by the cytogenetics laboratory from referrals for delayed development, or mental retardation, resulting from many causes. Molecular and cytogenetic diagnosis of fragile $\mathrm{X}$ syndrome might be complicated by a small number of cases which do not have an unstable element. These could result from mutation within the associated gene other than at the CCG repeat, such as a point mutation, microdeletion, or microduplication. One deletion has been detected and the extent of this deletion is being characterised in an affected boy where the pfxa3 probe failed to hybridise to PstI or EcoRI digested DNA (unpublished data).

PCR amplification of the polymorphic CCG repeat from normal chromosomes and those with small CCG amplifications now enables direct sizing of alleles at the fragile $\mathrm{X}$ locus. ${ }^{8}$ This analysis has established the allele distributions of this polymorphism in normal males and in male transmitters and confirmed an upper limit for amplification of $600 \mathrm{bp}$ in transmitting males. Accurate delineation of these two groups by direct PCR genotyping would be preferable to separation based on estimation of PstI fragment size by Southern analysis. The PCR results, however, must be interpreted with caution given the extent of somatic instability in affected males, which may give rise to one or more additional bands in the normal to transmitter range. This inherent difficulty precludes PCR analysis of CCG amplification from prenatal diagnosis. Conversely, direct PCR genotyping will exclude carrier state in females with two normal alleles as long as each corresponds to the unaffected allele of a parent or sib. Direct PCR genotyping has not been demonstrated for the large amplifications in excess of $600 \mathrm{bp}$. It is most likely that, together with PCR based genotyping of flanking AC repeats, ${ }^{11}$ the PCR analysis of the fragile X CCG repeat will supplement, rather than replace, direct detection by Southern blots.

\section{Note added in proof}

Experience with direct molecular diagnosis of fragile $\mathrm{X}$ has also been reported using the probe StB12.3 by Rousseau et al (N Engl $\mathcal{f}$ Med 1991;325:1673-81).

This work was supported by grants from the National Health and Medical Research Council of Australia and the Adelaide Children's Hospital Research Trust.

1 Sutherland GR, Baker E. The common fragile site in band q27 of the human $X$ chromosome is not coincident with q27 of the human X chromosome is not

2 Suthers GK, Mulley JC, Voelckel MA, et al. Genetic mapping of new DNA probes at Xq27 defines a strategy for DNA studies in the fragile X syndrome. $A m \mathcal{F}$ Hum Genet 1991;48:460-7.

3 Sherman SL, Morton NE, Jacobs PA, Turner G. The marker $(\mathrm{X})$ syndrome: a cytogenetic and genetic analysis. Am $\mathcal{F}$ Hum Genet 1984;48:21-37.

4 Sherman SL, Jacobs PA, Morton NE, et al. Further segregation analysis of the fragile $X$ syndrome with special
reference to transmitting males. Hum Genet 1985; 69:289-99.

5 Yu S, Pritchard M, Kremer E, et al. Fragile X genotype characterised by an unstable region of DNA. Science 1991;252:1179-81.

6 Oberlé I, Rousseau F, Heitz D, et al. Instability of a 550base pair DNA segment and abnormal methylation in fragile X syndrome. Science 1991;252:1097-102.

7 Verkerk AJMH, Pieretti M, Sutcliffe JS, et al. Identification of a gene (FMR-1) containing a CGG repeat coincident with a breakpoint cluster region exhibiting length ent with a breakpoint cluster region exhibiting length

$8 \mathrm{Fu}$ Y-H, Kuhl DPA, Pizzuti A, et al. Variation of the CGG repeat at the fragile $X$ site results in genetic instability: resolution of the Sherman paradox. Cell 1991;67:1047-58.

9 Yu S, Mulley J, Loesch D, et al. Fragile X syndrome: unique genetics of the heritable unstable element. $A m \mathcal{F}$ Hum Genet 1992;50.

10 Kremer EJ, Pritchard M, Lynch M, et al. Mapping of DNA instability at the fragile $X$ to a trinucleotide repeat sequence p(CCG)n. Science 1991;252:1711-14

11 Richards RI, Holman K, Kozman H, et al. Fragile X syndrome: genetic localisation by linkage mapping of two microsatellite repeats $F R A X A C 1$ and $F R A X A C 2$ which immediately flank the fragile site. $\mathcal{f}$ Med Genet 1991;28:818-23.

12 Mulley JC, Gedeon AK, Thorn KA, Bates LJ, Sutherland GR. Linkage and genetic counselling for the fragile $X$ GR. Linkage and genetic counselling for the fragile using DNA probes 52A,

13 Richards RI, Shen Y, Holman K, et al. Fragile X syndrome: diagnosis using highly polymorphic microsatellite markers. Am ₹ Hum Genet 1991;48:1051-7.

14 Dausset J, Cann H, Cohen D, Lathrop GM, Lalouel JM, White $\mathbf{R}$. Centre d'Étude du Polymorphisme Humain (CEPH): collaborative genetic mapping of the human genome. Genomics 1990;6:575-7

15 Mulley JC, Turner G, Bain S, Sutherland GR. Linkage between the fragile $\mathrm{X}$ and $F 9, D X S 52$ (St14), DXS98 (4D-8) and DXS105 (cX55.7). Am $\mathcal{f}$ Med Genet 1988;30:567-80.

16 Romain DR, Chapman CJ. Fragile site Xq27.3 in a family without mental retardation. Clin Genet (in press).

17 Voelckel MA, Philip N, Piquet C, et al. Study of a family with a fragile site of the $\mathrm{X}$ chromosome at Xq27-28 without mental retardation. Hum Genet 1989;81:353-7.

18 Sutherland GR, Baker E. Characterization of a new rare fragile site easily confused with the fragile X. Hum Mol Genet (in press)

19 Sutherland GR, Gedeon A, Kornman L, et al. Prenatal diagnosis of fragile $\mathrm{X}$ syndrome by direct detection of the characteristic unstable DNA element. $N$ Engl $f \mathrm{Med}$ characteristic uns

20 Hirst $M$, Knight $\mathrm{S}$, Davies $\mathrm{K}$, et al. Prenatal diagnosis of fragile X syndrome. Lancet 1991;338:956-7. 